\title{
STUdent AgenCy in Translator Training: SETTING A FRAMEWORK FOR GOOD PRACTICES
}

\author{
MARIA GoNZÁLEZ DAVIES \\ FPCEE-Blanquerna, University Ramon Llull, Barcelona, Spain \\ mariagd@blanquerna.url.edu
}

\begin{abstract}
Both teacher and student agency have been discussed and researched for quite some time in different learning contexts. Here, I will present a general framework for pedagogical practices that enhance translator education by promoting student agency defined as the process through which learners become capable of strategic actions which form the basis for autonomy and confidence in their own proficiency and effectiveness. I will suggest how student agency and collaborative and situated learning can interact to provide students with professional and relational skills that set the basis for the development of autonomous strategic learning. This combined approach involves the acceptance and use of planned and spontaneous learning opportunities embedded in contextualised activities, tasks, and projects. Some practical examples will illustrate the main points.
\end{abstract}

Keywords: collaborative learning, self-concept, situated learning, student agency, translator training

\section{Defining Student Agency}

As far back as 1976, Wilss, and, later, Deslile (1980) questioned translation training based solely on the translation product, with assessment revolving solely around mistakes. They already advocated for active process and learner-centred approaches to training where the roles of teachers and learners are revisited. Much has been done since then to follow this path in research and observation of best practices in translator training (cf. amongst others, Colina 2003; González-Davies 2004; Hurtado 1999; Kelly 2005; Kiraly 2000; Kussmaul 1995; Massey et al. 2019). Also, further informed work on translator training is shared worldwide in publications such as The Interpreter and Translator Trainer, or International Journal of Interpreters Education. However, as is happening in other fields related to teaching and learning such as Psychology and Education, much remains to be explored, especially regarding how attitudes can affect performance. I argue that the time has come to find ways to favour interdisciplinary exchanges to improve didactics and therefore, the quality of translation and interpreting competence, both regarding online and face-to-face teaching modes. Hence, in this paper I will 
suggest a general framework for pedagogical practices that enhance translator education by promoting student agency, collaborative and situated learning. According to Hurtado (2019: 55), mainly two pedagogical approaches have developed in translator training over the years:

A. Transmissionist approaches, which are teacher and product-centred:

- Traditional translation didactics

- Contrastive approaches

- Theory-based approaches

B. Learner and process-centred approaches

- Process-based approaches

- Objectives-based approaches

- Task and project-based approaches

- Socio-constructivist approaches

- Competence-based training

- Situated training

The preferred guiding pedagogical approach embraced in this article conforms to the second block, where the learners become active participants in their learning process, developed mainly in a situated collaborative environment that follows socio-constructivist principles. This pedagogical framework is flexible and appropriate for all levels of proficiency, most language combinations, most institutions and learning contexts, and most topics and specializations in translator training. In this setting, student agency, defined as the process through which learners become capable of strategic actions which form the basis for autonomy and confidence in their own proficiency and effectiveness, takes centre stage (González-Davies and Enríquez 2017).

With this in mind, one way to work is to go back to the classics and address Delors' dimensions for global education (1996), not only savoir and savoir faire, but also the often-neglected savoir être”. This links with an ecological approach to teaching and learning where instruction is viewed as a dynamic, non-linear, adaptative process that acknowledges the complexity of teaching and learning and considers not only the cognitive processes but also emotions, memories, anticipations, and empathy (Bristor and West 1996/97; González-Davies 2020; Haro-Soler and Kiraly 2019; Kramsch 2018; Snyder 2013; UNESCO 2015). In fact, savoir être is now increasingly being addressed in research as teaching and learning shifts from a perspective of industrially efficient education where the stakeholders are not much more than cogs in a wheel, to a sociocultural perspective where they become people in networks. This approach considers internal and external factors related to the teaching and learning process, as 
already put forward by Arnold (1990); Bandura (1986), Damasio (1994), and Hönig (1991), amongst others. Increasingly, learning based on dichotomies (practice vs theory, reason vs emotions, and so on) is giving way to a holistic approach that considers and integrates the whole set of skills and strategies needed to advance learning: cognitive (assimilating the subject matter), metacognitive (managing learning), and socio-affective (handling emotions and attitudes), explained in more detail below (González-Davies 2017; 2018; 2020; Oxford 2011). Thus, we may transform our teaching practices, so that the aim of the learning process is not to produce cogs in a wheel but to include people in networks by preparing our students for lifelong learning and the global skills that go with it. In Pietrzak's words (2019: 97): "Due to the dynamic nature of the translator's occupation, it is difficult to predict what specific skills will prove useful for novice specialised translators in their professional career". This is where student agency comes into play as a dimension that has been gaining prominence in translator training recently and can be directly related to psycho-social aspects of the learners, such as self-concept, self-beliefs, and self-regulation (cf. Göpferich et al 2009; Haro-Soler 2019; Haro-Soler and Kiraly 2019; HubscherDavidson 2018; Kelly 2005; PACTE 2009; Pietrska 2019, amongst others).

Collaborative and situated environments are especially favourable to the development of autonomous strategic learning since this approach involves reflective practice through both planned and spontaneous learning opportunities embedded in contextualised activities, tasks, and projects. Here, the teacher "scaffold[s] learning, provide[s] substantial support for knowledge construction early in the course or programme, and gradually relinquish[es] control over the learning to the students themselves" (Kiraly 2000: 68) so that the learner is empowered by means of tuning the different elements that intervene in the instructional process and by shifting the teacher's sole focus from the object of learning to include the person and the community where learning takes place (Bristor and West 1996). The notion of agency is not simply about handing control over to the learner. Rather, it involves creating a role-reversal context where the learners are actively involved in learning and well-being. Effective student agency involves meeting some recurrent aspects to be found in the literature, such as:

- The initiative or self-regulation of the learner since, before learners can exercise agency in their particular learning context, they must hold the belief that their behaviour and their approach to learning is actually going to make a difference for them.

- Positive interdependence with the sociocultural context of the classroom, which implies managing socio-emotional skills and strategies appropriately because there are individual and collective consequences for the decisions each learner makes and each action they take.

- Explicit individual and group reflective processes (previous and post) should accompany all tasks and actions. 
Emotions play a relevant role in this context. As more research in neuroscience emerges, the role of emotions in learning is becoming well established, along the lines stated by Immordino-Yang and Damasio (2007: 9):

First, neither learning nor recall happen in a purely rational domain, divorced from emotion, even though some of our knowledge will eventually distil into a moderately rational, unemotional form. Second, in teaching students to minimize the emotional aspects of their academic curriculum and function as much as possible in the rational domain, educators may be encouraging students to develop the sorts of knowledge that inherently do not transfer well to real-world situations.

Positive and negative emotions are interrelated: for instance, how do anxiety and lack of confidence affect cognitive performance and social skills? As far back as 1908, the "Yerkes-Dodston law" ascertained that a certain level of stress, eustress, is enabling and boosts learning, whereas after a peak, it becomes dis-stress, which is weakening and damaging. Therefore, a relation between anxiety, behaviour, and cognitive performance seems to be clearly established (Mcintyre 1995). Teachers' experience also underlines that a high demand in class may lead to anxiety and worry, so that cognitive performance is diminished because of divided attention between the cognitive and the emotional tension. This leads to negative self-efficacy beliefs and, thus, to a negative self-concept which further impairs performance.

Agency then is directly related to the development of a positive self-concept, which balances and reconciles self-efficacy beliefs and actual self-efficacy: Selfefficacy beliefs refer to the individual's perception of their abilities to perform a task whereas the abilities that a person possesses to perform a specific task establish their self-efficacy. As Haro-Soler and Kiraly (2019) explain, these two terms are used as synonyms in the literature in Educational Psychology and, more particularly, in Bandura's (1986) Social Cognitive Theory, where self-efficacy and self-efficacy beliefs play a major role and are accompanied by self-esteem. Specifically, in translator training, a positive self-concept implies "a sense of the purpose of the translation, an awareness of the information requirements of the translation task, a self-evaluation of capability to fulfil the task, and a related capacity to monitor and evaluate translation products for appropriateness" (Kiraly, 1990: 100, in Haro-Soler and Kiraly 2019). Thus, in situated learning the learners' capacity to think and act like professionals is encouraged. They are exposed to real-life and/or highly simulated work environments and tasks, both inside and outside the classroom. Under this approach, the curricular design is driven by tasks and real-life professional demands, as well as other contextual factors such as institutional, social, geographical, socio-economic constraints, market conditions, institutional practices, budgetary issues, or resource availability, rather than a predetermined closed syllabus (González-Davies and Enríquez 2017). In this situated pedagogical framework, Richards' and Rodgers' three levels of 
instructional organization provide appropriate guidelines: from Approach through Design to Procedures (1986/2014).

\section{The pedagogical framework: Collaborative and situated learning}

\subsection{The Collaborative-Situated Approach}

The approach, as presented by Richards and Rodgers (1986/2014), refers to the theoretical framework that teachers attach to their beliefs regarding teaching, learning, and, in translator and interpreter training, to translation. The perspective embraced will colour classroom dynamics (design) and the tasks for the students to fulfill (procedures). The translation-oriented procedures that will make the approach and design visible can take the shape of either specific activities, that is, brief, concrete exercises that help students practice specific points; tasks or didactic sequences, which are coherent chains of activities with the same global aim; or projects defined as multi-competence assignments that enable students to engage in related pedagogical and professional activities and tasks while working together on an authentic or simulated end product. Tasks are more tightly structured than a project and more controlled by the teacher (González-Davies 2004).

The collaborative-situated approach follows socio-constructivist premises (Vygotsky 1978; Kiraly 2000) and can be adapted to both face-to-face and online learning to make the most of the opportunities offered by each mode. For instance, while remote learning poses challenges for teamwork, it also broadens the range of available collaborators. A first step to work effectively according to these premises involves establishing and accepting a community of practice where diversity is not only embraced, but also capitalized on. Within this community, more experienced students may act as more knowledgeable peers, that is, as members of the community who, alongside the teacher, can help other members progress. In other words, the more knowledgeable peers can adopt an active role in guiding the other students so that they can reduce the gap between what they know (self-efficacy), what they think they know (self-efficacy beliefs), and the desired outcome, which, in translation studies, is to acquire appropriate personal, professional, and academic translator competences. Thus, the teacher's task is to gauge the contributions of each member of the community of practice to help them move from being novice to experts, according to their level. This development is aided by scaffolding that is, specific assistance with both strategic action and reflection around the topic at hand. So, student agency is underscored by socioconstructivism as, according to Vygotsky, "[a]ny higher mental function [is] external because it was social at some point before becoming an internal, truly mental function" (1960/1981:162). That is, individual and teamwork will combine 
to help the students become efficient autonomous professionals with a solid selfconcept as translators and, in some cases, as researchers.

Previous knowledge and experiences are not the same for everyone. This is sometimes forgotten by some teachers who believe - probably unconsciously - in a tabula rasa approach, which favours a uniform treatment of all pedagogical actors and actions. The fact of incorporating new knowledge into old knowledge may prompt the development of new outlooks and a reframing of previous perceptions. Teachers play a key role here when, instead of keeping to a strict syllabus, they accept and incorporate unexpected affordances in the teaching and learning process, that is, in Kiraly's words, the provision of "substantial support for knowledge construction and gradually relinquish(ing) control over the learning environment to the students themselves" (2000: 68). Although with some differences, this approach to learning reconciles Piaget's constructivist and Vygotsky's socio-constructivist outlooks (cf. Klimkowski 2020 for an updated review of constructivist and socio-constructivist approaches to translation and education).

In an agentive approach, translation is viewed as a process and a product of communication, in line with real-life practices and research in Translation Studies, and in opposition to static definitions that describe translation only from a linguistic and quasi-literal perspective. As a process, translation was defined by Hatim and Mason as "a dynamic process of communication" (1990: 223) that strives to transmit the source message and create a desired effect among target readers or listeners. As a product, translation is considered here to be any text, verbal or visual, that is related to a source text, as well as "any text that is accepted in the target culture as being a translation" (Chesterman 1997: 59), whether in the same language or code, or in different ones: intra- or inter-linguistic translation and intra- or inter-semiotic translation (Jakobson 1956/2000: 232; GonzálezDavies 2017; 2018; 2020). Thus, both instrumental and hermeneutic approaches to Translator Training are integrated in the pedagogical framework (Venuti 2017: introduction).

As to professional translator competence, in Pym's words, its efficient application implies world knowledge, teamwork cooperation, and selfconfidence. The translator should also be capable of rendering the same source text in many ways, depending on the assignment (2003: 489):

As an interpersonal activity working on texts (of whatever length or fragmentary status), the training of translators involves the creation of the following two-fold functional competence $(\ldots)$ :

- $\quad$ The ability to generate a series of more than one viable target text (TTI, TT2 ... $\mathrm{TTn}$ ) for a source text (ST);

- The ability to select only one viable TT from this series, quickly and with justified confidence. 
For training purposes, to achieve this two-fold functional competence, Kelly's pedagogically-oriented definition of translation competence is especially useful as it clearly includes the mentioned three dimensions related to a balanced and well-grounded syllabus design, namely, cognitive, metacognitive and socioaffective: "Translation competence is the macro-competence that comprises the different capacities, skills, knowledge and even attitudes that professional translators possess and which are involved in translation as an expert activity" (2002:14-15). This macrocompetence can be broken down into six subcompetencies. Although they are all connected, specifically, competences 2, 5 and 6 in her revised proposal are related to the social and emotional dimensions related to student agency (2005:32-33):

1. Communicative and textual: This covers active and passive skills in the languages involved, together with awareness of textuality and discourse in the cultures involved.

2. Cultural and intercultural: Culture here refers not only to encyclopaedic knowledge of history, geography and so on, but also to the values, myths, perceptions, behaviours and textual representations of these.

3. Subject area: Basic knowledge of subject areas and access to specialised documentation to solve translation problems.

4. Professional and instrumental: Use of documentary resources of all kinds, use of IT and traditional tools for professional practice. Basic notions for managing professional activity (contracts and so on).

5. Attitudinal or psycho-physiological: Self-concept, concentration, memory, initiative and so on.

6. Interpersonal: Ability to work with other professionals, negotiation and leadership skills.

7. Strategic: Organizational and planning skills, problem identification and solving, monitoring, revision and so on.

These complementary professional and pedagogical approaches to the acquisition of translator competence can be connected to a three-dimensional strategic framework to achieve pedagogical balance. This framework is composed of cognitive, metacognitive, and socio-affective learning strategies (Oxford 2011: 16):

- Cognitive strategies favour "constructing, transforming, and applying (...) knowledge". Some examples are the awareness of textuality and discourse, knowledge of subject areas, use of ICT tools, knowledge of translation strategies, and control of specialized terminology.

- Meta-cognitive strategies foster "managing and controlling (...) learning in a general sense, with a focus on understanding one's own needs and using and adjusting the other strategies to meet those needs". These may include organisational and planning skills, self-assessment and revision, problem identification and problem-solving, keeping to deadlines and the assignment, and web-mining

- Social and affective strategies refer to "handling emotions, beliefs, attitudes, and motivation in (...) learning". These focus on, for instance, the ability to work with 
other professionals, the development of negotiating skills with clients and of intercultural communication issues, and flexibility and tolerance of ambiguity.

Once the competential and the strategic frameworks have been outlined, both the teachers' and the learners' tasks become informed and may sustain possible pedagogical dilemmas in both face-face-to-face and online learning in an empowered and effective way, for example: How can individual skills and strategies relate to team skills and strategies optimally? How can professional and academic elements relate optimally?

One way to reflect on these questions, which are directly relevant to the development of the student-translators' self-concepts, is to apply integrated procedures, that is, tasks where competence and strategies are connected explicitly and meaningfully. Two procedures, which can also be carried out in virtual learning environments, are presented below to illustrate this point: Restating and Mind Maps.

Restating. After a general explanation, the teacher breaks groups (in class or using the online resources available in most interactive platforms) and gives the students time to explain to each other what has been said using their notes or going back to the teacher's audio-visual aids (power point, you tube video etc.) as they need to (cf. the "flipped classroom" approach). This can be done in any language (in fact, it can be a useful interpreting exercise) and can be carried out in 5-10 minutes, as needed, and not necessarily at the end of the class.

This activity involves the ability to select only one viable target text from several multimodal texts (the teacher's explanation and support material, the text they are working on (if any), their own notes, and so on), quickly and with justified confidence (cf. Pym's description of translator competence above). As to the strategic framework, Oxford's list of learning strategies can be easily related to Kelly's list of translation competences:

- Cognitive: Communicative and textual, subject area

- Metacognitive: Strategic, professional, and instrumental

- Socio-affective: Attitudinal or psycho-physiological, interpersonal

Moreover, this brief collaborative activity ensures that the concepts have been understood, it boosts concentration, and may signal the sections in a didactic sequence, thus conforming to a balanced and informed pedagogical procedure.

Mind Maps. Another successful way of making the strategies, dimensions, and competences explicit and empowering the students is for them to work with the mind map activity. A mind map is a diagram that depicts ideas and concepts, terminology, etc. in a personal, flexible, and clear way. Quite a few free tools to create mind maps online can be found easily (for example, Coggle, Semantik, Compendium and others). This technique can be adapted to any subject matter as it fosters reflection on its progress and on the students' expectations and capabilities. For instance, in medical translation, the students should break into 
pairs or groups of three on the first day. They then write "Medical Translation" in the centre of the page and draw lines that lead to related subtopics. Each subdivision can then include words, expressions, and other concepts, and can be expanded until they have finished. Then, the groups work together and compare their mind maps. If done online, told such as padlets (see, for example, https://thedigitalteacher.com/reviews/padlet) can be used to pool their ideas. Finally, a class discussion may follow where the aims and syllabus are presented by the teacher and, adjusted to the detected initial level of the students to cater for their real needs. When the subject ends, the students and the teacher may revisit their mind maps or, alternatively, this can be done regularly to update and modify them as required (González-Davies 2017: 73).

To summarize the approach, in collaborative and situated translator training, the focus is not on translation and interpreting, but on the translator and interpreter, fore fronting emphasising the person who learns, not the object of learning. In the classroom, the emphasis is on the completion of authentic or simulated tasks in meaningful contexts. Inter-action comes before individual action in this context, although both are included. In this way, reflective declarative (savoir) and procedural (savoir faire) knowledge are built through positive social interaction (savoir être) in a specific context (situatedness) to favour student agency and, thus, the attainment of personal, professional, and academic expertise.

\subsection{Design for collaborative-situated translator training}

The second level of Richards' and Rodgers' instructional framework, i.e., design, relates mainly to classroom dynamics and syllabus design. Following the collaborative-situated approach, classroom and syllabus design should favour processes that enable the students to develop from novices to experts through scaffolding, individually and collaboratively, while coping with diversity.

\subsubsection{Classroom dynamics}

A first consideration connects teaching styles, classroom dynamics and syllabus design, including the use of the extended classroom. Teaching can be teachercentred (mostly, transmissionist), student-centred (mostly, transactionist), or student agency-oriented (mostly, transformationist).

Extreme transmissionist approaches to teaching regard the instructor as a formal authority and expert, who delivers a uniform discourse to all the students without considering diversity, their previous knowledge and experiences, or identities. They are expected to follow a "read and translate" procedure and take notes. Instruction is product-based and there is little interaction between learners. The procedures are cognitive only, strictly planned, with closed answers, and assessment is based on uniform measures of learning success. 
On the other hand, the transactionist approach leans towards constructivism, whereas the transformationist approach leans towards socio-constructivism. However, both the transactionist and transformationist approaches have certain characteristics in common: they are process- and product-based, and they include a belief in classroom democracy as well as in dialogue and in building a positive learning atmosphere achieved through discovery and experimentation. Moreover, both these approaches are most suited to our rapidly changing classroom conditions where, in blended and virtual learning modes, design and procedures need to be highly interactive and empower student autonomy. Indeed, these approaches work explicitly on the competences that fit in well with the challenges posed by a globalised world.

Concerning some of the differences between them, in a transactionist approach, the teacher is regarded as an expert and facilitator who guides and controls the outcomes, sets goals and tasks, but still holds the answers. Thus, the activities are planned, and discovery is controlled. Assessment is still based on uniform measures of learning success. In contrast, in a transformationist approach, the teacher is a more knowledgeable peer who facilitates, coordinates and delegates learning. Often, as when working on authentic translations for real clients, discovery is shared by the students and the teacher, so an active participation of learners is expected at every stage of the teaching/learning process. Procedures focus on authenticity and are designed to offer and accept (spontaneous) opportunities for learning, i.e., affordances. Although some may be planned, they mostly revolve around unplanned project work, with students experiencing the ins and outs of real-life translation assignments.

According to (socio)constructivist premises, the optimal pedagogical framework is an eclectic approach to all three modalities, leaning heavily on the transactionist and transformationist. Although collaborative and situated learning typically involve the production of authentic translations where external agents or clients assess and accept a translation as publishable, if necessary, this process can also be simulated through role-playing among students and teachers. Students can thus feel guided and supported by the teacher while experiencing the risk of making decisions and justifying their work with a simulated client. The clients can be real, or can be role-played by other teachers and their students working in a tandem-learning context simulating real-world transactions which, increasingly, take place online.. Also, professionals can be invited to lead workshops and give talks, to help with a project at crucial stages, to evaluate the students' translations and so on. These professionals can be related to the students' Practicum, collaborate as external speakers in the institution, or belong to an NGO or a nonprofit organization, so that this is a win-win situation where the students, the teacher, and the professional world all benefit. 


\subsubsection{Syllabus design}

A syllabus can be structured, semi-structured or open. A semi-structured syllabus that favours student agency enables the incorporation of unplanned spontaneous suggestions and unexpected needs that may emerge. The main components of the syllabus include relevant translation competences, specific aims or expected outcomes, procedures assigned to the students (activities, tasks, and projects), and bibliography. Procedures alternate between individual and team tasks, sometimes in homogeneous and sometimes in heterogeneous groups, during the process. The final product is sometimes individual and sometimes the result of teamwork (González-Davies 2017: 72). All the above implies that specific pedagogical scaffolding is needed to integrate collaborative and situated practices effectively. The preferred design given the collaborative-situated approach is an integration of activities and tasks in didactic sequences or projects. Here follow two examples that can be implemented in both face-to-face and virtual sessions:

- Project work only, which is a pure socio-constructivist transformationist approach

- Project work carried out in parallel to the didactic sequences, a more eclectic approach where planned activities and tasks share space with unplanned activities and tasks that surface from the students' questions and specific needs.

Importantly, social and affective strategies should be included explicitly and regularly to favour group-binding. Rapport can grow, for example, through icebreakers, self-reflection techniques, and pair and group work. Also, a session should be devoted to teamwork techniques (turn-taking, negotiating, and so on) and to establishing clear group aims and dates that can be flexible, if justified. Most of these strategies are eminently adaptable for remote teaching, although this kind of adaptation goes outside the remit of this article.

As to assessment, in this approach both the process and product are evaluated, sometimes by an external evaluator or client in the case of an authentic project or simulations (González-Davies 1998; 2004; 2017). Rubrics are implemented for self, peer, and teacher assessment and value the cognitive, metacognitive and socio-emotional dimensions along with translator competence. As an example, here follows one of the rubrics used at the annual seminars on Collaborative Translator Training (CTT) ${ }^{1}$ where the participants were pre- and in-service translation teachers. Their final assignment was to design a didactic sequence following the premises of a collaborative and situated approach as presented here.

1 The CTT was held alternately at the University of Vic and the University Ramon Llull in Spain, and the University of Auckland in New Zealand. The seminars were organised by the author of this article. Seminars leaders have included Don Kiraly, Richard Samson, Vanessa Enríquez and Frank Austermhül. 
Table 1. Rubric

\begin{tabular}{|c|c|c|c|c|}
\hline \multicolumn{5}{|c|}{ Designing a didactic sequence in a collaborative and situated pedagogical framework } \\
\hline $\begin{array}{c}\text { Criteria } \\
\text { and } \\
\text { comments }\end{array}$ & $\begin{array}{c}\text { A. } \\
\text { The learning } \\
\text { material is } \\
\text { original and } \\
\text { innovative. It } \\
\text { contains clear } \\
\text { aims, timing, } \\
\text { grouping, } \\
\text { sequencing and } \\
\text { steps. It involves } \\
\text { negotiation and } \\
\text { teamwork. It is } \\
\text { relevant to the } \\
\text { students and } \\
\text { involves external } \\
\text { agents }\end{array}$ & $\begin{array}{c}\text { B. } \\
\text { The learning } \\
\text { material is } \\
\text { appropriate. It } \\
\text { contains most of } \\
\text { the components of } \\
\text { a clearly designed } \\
\text { procedure. It } \\
\text { involves some } \\
\text { negotiation and } \\
\text { teamwork. It is } \\
\text { quite relevant to } \\
\text { the students and } \\
\text { does not involve } \\
\text { external agents }\end{array}$ & $\begin{array}{c}\text { C. } \\
\text { The learning } \\
\text { material is } \\
\text { adequate. It } \\
\text { contains some of } \\
\text { the components of } \\
\text { a clearly designed } \\
\text { procedure. It } \\
\text { involves little or } \\
\text { no negotiation and } \\
\text { teamwork. It is } \\
\text { somewhat } \\
\text { relevant to the } \\
\text { students and does } \\
\text { not involve } \\
\text { external agents }\end{array}$ & $\begin{array}{c}\text { D. } \\
\text { The learning } \\
\text { material is } \\
\text { inadequate. It } \\
\text { contains few or } \\
\text { none of the } \\
\text { components of a } \\
\text { clearly designed } \\
\text { procedure. It } \\
\text { involves little or } \\
\text { no negotiation and } \\
\text { teamwork. It is } \\
\text { not relevant to the } \\
\text { students and does } \\
\text { not involve } \\
\text { external agents }\end{array}$ \\
\hline \multicolumn{5}{|l|}{ Student 1} \\
\hline Student 2 & & & & \\
\hline
\end{tabular}

Some examples of projects prepared by participants in the CTT courses are given here:

- Project Management and Terminology. The Summer Project. The aim is to have students experience the whole process of a translation project and be involved in every phase (U. Vic, Spain, 2005).

- Miracles in the Making: The Pohutukawa Method. The aim is to train adult native speakers of languages of low diffusion to produce translations at a professional level (U. Auckland, New Zealand, 2014).

\subsection{Further procedures to favour student agency}

According to David Nunan (1995: 40), classroom procedures can be pedagogic, that is, planned and controlled by the teacher, and real-life, that is, involving simulated or authentic material and processes. Here are some examples of both modalities classified as activities, tasks or didactic sequences, and projects. The main idea behind all these can be adapted to different levels, language combinations, as well as in face-to-face and online learning contexts with online free ICT tools. 


\subsubsection{Activities}

Jigsaw. Divide an assignment into subtasks. Pairs or small groups of students carry out their task and meet regularly face-to-face or online to discuss ideas and progress. They regroup as necessary until the assignment is completed.

Fishbowl debates. In small groups, the students discuss a topic adopting different roles: Student A is in favour of a position, Student B is against it and Student $\mathrm{C}$ takes notes and lists the pros and cons of each position. Finally, they write a Position Paper together or individually. They change roles. If carried out online, the mainstream interactive platforms offer the resources to break groups (Meet, Zoom, Teams, and so on)

Visualisation and multimodality. Use pictures, audio material and so on to recreate senses and emotions as well as to work on the cognitive dimension. This results in a more personal experience and links the person with the topic.

Guided activities. Carry out cognitively challenging activities by scaffolding each other, for example, guided sight translation. The teacher or the students choose two texts in the L1 related to a relevant topic and each student receives one. The students work in pairs, Student A with one of the texts and Student B the other. Individually, each student translates his/her text with the help of any resource material needed. Once they have finished, Student A carries out a sight translation of the text he or she has not translated, that is, Student B's text. Student B listens and, without interrupting, underlines any interesting points worth commenting on. Student B sight translates Student A's text and the same procedure is followed. Students A and B comment on the points of translation that could be improved. The teacher presents a possible translation of the texts and a class discussion may follow (González-Davies 2004: 66).

\subsubsection{Didactic sequences or Tasks}

Understanding translation theory through reflective action. This task combines three collaborative activities: Jigsaw, Mind Maps, and Restating. When the students need to analyse and discuss a complex article, after they have all read it, divide it into sections and give each section to a group. Then, the students sit in small groups and draw a mind map with the main ideas in their section. Finally, the students form new (bigger) groups with a member from each of the previous groups. Each member explains the part they have worked on using the mind map as a guideline. When all the parts have been discussed, they all restate the article, and discuss doubts, questions and interesting points.

Online peer project guidelines (Online MA programme in Specialised Translation, U. Vic, Spain, 2008-2019). Subject: Translator Training. Codesigners: Maria González-Davies, Lucrecia Keim and Richard Samson: https://www.uvic.cat/es/master-universitario/traduccion-especializada. These are the guidelines presented to the students: 
Assignment: A slideshow presentation at a Translator Training Conference

The presentation should consist of multimodal slides and an accompanying transcript of speaker's notes. Optionally, these notes can be recorded as an audio track and synchronized with a slide hosting service.

- Topic: A specialized translation unit to be taught following a collaborative and situated approach.

- Contents of the presentation: Please specify the teaching setting, your approach to teaching and to translation, the design of the unit (level, sequencing, time, class dynamics, and so on), the chosen procedures (reallife or pedagogic, steps, examples, and so on). You should design a teaching unit for about 16-20 hours of teaching time. It can be related to any specialized translation field.

- Peer support: Pair up with another student with similar interests or working in a similar context pair up to advise and give feedback online to each other on your projects. By working together on the process, your final products will improve. Also, by giving feedback to another student, you will be improving your creative and critical skills, thus learning to (self)-monitor in a practical way through an authentic situation. You should interact with your partner in two stages (or more if you wish to do so).

- Peer evaluation: send a text file with details of the feedback you gave to your partner, the support you received and your evaluation of the final project, together with your feelings about the experience of this task. You should bear in mind that the teaching unit presented should show quality, as well as practicality and clarity from the perspective of another teacher (who we imagine might be the substitute of the author of the unit).

\section{Conclusions}

In this article, I have defined student agency from a sociocultural perspective favouring a pedagogical framework based on situated and (socio)constructivist premises. Despite the pandemic, I have suggested how a collaborative-situated approach to translator and interpreter training can also be applied effectively in blended and virtual learning contexts. The proposed framework connects cognitive, metacognitive, and socio-affective learning strategies with two models of translation competence that, taken together, may reconcile professional and pedagogical practises to foster the construction of a positive self-concept in the learners. This entails the belief that aptitudes and attitudes influence each other. In Jane Arnold's words (2011: 14): 
question of how affect can maximize cognition, of how an integration of affect and cognition can enhance learning.

Finally, specific collaborative-situated procedures to implement a collaborative and situated approach to training, which are easily transferable for online teaching, have been presented to illustrate the main points. In spite of these adaptations, however, the present challenging educational situation has brought into the open the relevance of exploring and suggesting informed pedagogic practices that relate to a globalised world where online interaction has become indispensable. Therefore, more research is needed along these lines.

\section{References}

Arnold, Jane (1999) Affect in Language Learning, Cambridge, Cambridge University Press.

Arnold, Jane (2011) "Attention to Affect in Language Learning “, Anglistik: International Journal of English Studies 22: 11-22.

Bandura, Albert (1986) Social Foundations of Thought and Action: A Social Cognitive Theory, Englewood Cliffs, NJ, Prentice-Hall.

Bristor, Martha W. and Dorothy L. West (1996/97) "An Ecological Approach to Empower the Learner”, Human Ecology Review 3, no. 2, SHE-VIII Proceedings - 2: Human Ecology: Livelihood \& Liveability: 212-217.

Colina, Sonia (2003) Translation Teaching: From Research to the Classroom, Boston, McGraw Hill.

Damasio, Antonio (1994) Descartes' Error: Emotion, Reason and the Human Brain, New York, Avon Books.

Delisle, Jean (1980) L'analyse du discours comme méthode de traduction, Ottawa, Presses de l'Université d'Ottawa.

Delors, Jacques (ed) (1996) Learning: The Treasure Within, Paris, UNESCO.

González-Davies, Maria (1998) "Student Assessment by Medical Specialists: An Experiment in Relating the Undergraduate to the Professional World in the Teaching of Medical Translation in Spain" in Fischbach, Henry (ed) Translation and Medicine, ATA (American Translator's Association, Scholarly Monographic Series), Amsterdam, John Benjamins: 93-102.

González-Davies, Maria (2004) Multiple Voices in the Translation Classroom. Activities, Tasks and Projects, Amsterdam \& Philadelphia: John Benjamins.

González-Davies, Maria (2017) "A Collaborative Pedagogy of Translation" in Venuti Lawrence (ed) Teaching Translation. Programs, courses, pedagogies, Abingdon and New York: 71-79.

González-Davies, Maria. (2018) "The Use of Translation in an Integrated Plurilingual Approach to Language Learning: Teacher Strategies and Good Practices", Journal of Spanish Language Teaching, 4, no. 2: 124-135.

González-Davies, Maria (2020) "Using translation to develop plurilingual competence in high complexity schools" in Laviosa, Sara and Christine Ji (eds.) The Oxford Handbook of Translation and Social Practices, New York, Oxford University Press: 434-451.

González-Davies, Maria and Vanessa Enríquez Raído (eds.) (2017) Situated learning in translator and interpreter training: Bridging research and good practice, London and New York, Routledge.

Göpferich, Susanne, Arnt Lykke Jakobsen and Inger M. Mees (eds.) (2009) Behind the Mind: Methods, Models and Results in Translation Process Research, Copenhagen, Samfundslitteratur. 
Haro-Soler, María del Mar (2019) "Autoconfianza versus autoeficacia del traductor: propuesta terminológica y estado de la cuestión”, Cadernos de Tradução, Florianápolis 39, no. 2: 204-226.

Haro-Soler, Maria del Mar and Don Kiraly (2019) "Exploring self-efficacy beliefs in symbiotic collaboration with students: an action research project", The Interpreter and Translator Trainer 13, no. 3: 255-270.

Hartmann, Esa and Christina Hélot (2020) "Pedagogical affordances of translation in bilingual education", The Routledge Handbook of Translation and Education, Abingdon and New York, Routledge: 95-109.

Hönig, Hans (1991) “'Holmes' Mapping Theory' and the landscape of mental translation processes” in Leuven-Zwart, Kitty M. van and Ton Naaijkens, Translation Studies: The State of the Art, Amsterdam, Rodopi: 77-90.

Hubscher-Davdson, Séverine (2018) Translation and Emotion: A Psychological Perspective, Abingdon and New York, Routledge.

Hurtado Albir, Amparo (ed) (1999) Enseñar a traducir. Metodología en la formación de traductores e intérpretes, Madrid, Edelsa.

Hurtado Albir, Amparo (2019) "La investigación en didáctica de la traducción. Evolución, enfoques y perspectivas" in Tolosa Igualada, Miguel and Álvaro Echeverri (eds.) Porque algo tiene que cambiar. La formacion de traductores e interpretes: Presente \& futuro / Because something should change: Present \& Future Training of Translators and Interpreters, MonTI 11: 47-76.

Immordino-Yang, M.H. and Antonio Damasio (2007) "We Feel, Therefore We Learn: The Relevance of Affective and Social Neuroscience to Education", Mind, Brain and Education 1(o. 1: $3-10$.

Jakobson, Roman (1959/2000) "On Linguistic Aspects of Translation" in R. A. Bower (ed), On Translation, New York, Oxford University Press: 232-239.

Kelly, Dorothy (2002) "Un modelo de competencia traductora: bases para el diseño curricular" [A translation competence model: bases for curricular design], Puentes. Hacia nuevas investigaciones en la mediación intercultural, 1: 9-20.

Kelly, Dorothy (2005) A Handbook for Translator Trainers: A Guide to Reflective Practice, Manchester: St. Jerome.

Kiraly, Don (1990) Toward a Systematic Approach to Translation Skills Instruction, PhD diss., University of Illinois, USA.

Kiraly, Don (2000) A Social Constructivist Approach to Translator Education, Manchester, St Jerome.

Klimkowski, Konrad (2020) "Educational theory: from Dewey to Vygotsky" in Laviosa, Sara and Maria González-Davies (eds) The Routledge Handbook of Translation and Education, Abingdon and New York, Routledge: 29-46.

Kramsch, Claire and Zhang, L. (2018) The Multilingual Instructor, Oxford, Oxford University Press. Kussmaul, Paul (1995) Training the Translator, Amsterdam and Philadelphia, John Benjamins.

MacIntyre, Peter. D. (1995) "How does anxiety affect second language learning? A reply to Sparks and Ganschow", The Modern Language Journal 79, no. 1: 361-367.

Massey, Gary, Don Kiraly and Maureen Ehrensberger-Dow (eds.) (2019) The Interpreter and Translator Trainer 13, no. 3, Special issue: Training the Trainers.

Nunan, David (1989) Designing Tasks for the Communicative Classroom, Cambridge, Cambridge University Press.

Oxford, Rebecca (2011) Teaching and Researching Language Learning Strategies, Edinburgh, Pearson Education Limited.

PACTE (2009) (In alphabetical order: Beeby, A.; Fernández, M.; Fox, O.; Hurtado Albir, A.; Kozlova, I.; Kuznik, A.; Neunzig, W.; Rodríguez-Inés, P.; Romero, L.; Wimmer, S. Principal researcher: Hurtado Albir, A.) "Results of the Validation of the PACTE Translation Competence Model: Acceptability and Decision Making", Across Languages and Cultures 10 no. 2: 207-230. 
Pietrzak Paulina (2019) "Self-study Strategies in Project-based Specialised Translator Training”, Across Languages and Cultures. A Multidisciplinary Journal for Translation and Interpreting Studies 20, no. 1: 97-116.

Pym, Anthony (2003) "Redefining Translation Competence in an Electronic Age. In Defence of a Minimalist Approach", Meta 48, no. 4: 481-497.

Richards, Jack and Theodore Rodgers (1986/2014) Approaches and Methods in Language Teaching, London and New York, Routledge.

Snyder, Sean (2013) "The simple, the complicated and the complex: Educational reform through the lens of complexity theory”, OECD Education Working Papers, 96, OECD Publishing.

UNESCO (2015) Rethinking Education. Towards a global common good? Paris, UNESCO.

Venuti Lawrence (ed) (2017) Teaching Translation. Programs, courses, pedagogies, Abingdon and New York.

Vygotsky, Lev. S. (1960/1981) "The genesis of higher mental functions" in J. V Wertsch (ed), The concept of activity in Soviet psychology, Armonk, NY, Sharpe: 144-188.

Vygotsky, Lev S. (1978) Mind in Society: The Development of Higher Psychological Processes, trans. Michael Cole, Cambridge, Harvard UP.

Wilss, Wolfram (1976) "Perspectives and Limitations of a Didactic Framework for the Teaching of Translation.” in Brislin, Richard W. (ed) Translation: Applications and Research, New York, Gardner: 117-137.

Yerkes, Robert M. and John D. Dodson (1908) "The relation of strength of stimulus to rapidity of habit-formation", Journal of Comparative Neurology and Psychology, 18: 459-482. 